\title{
A política de desenvolvimento territorial rural no Brasil e a banalização do conceito de território
}

Agripino Soura Coelho Neto

Departamento de Educação da Universidade do Estado da Bahia (UNEB)

Recebido: 25/06/2013 Versão revisada (entregue): 12/08/2013 Aprovado: 23/10/2013

\begin{abstract}
Resumo
O vocábulo território nunca foi tão utilizado como nos últimos anos, seja como categoria explicativa acionada para a compreensão da dimensão espacial da sociedade, seja como palavrachave para a formulação de políticas públicas, seja como mote para as estratégias de movimentos sociais. Aqui se trabalha com a hipótese de que sua captura pela Política de Desenvolvimento Territorial Rural, do Ministério de Desenvolvimento Agrário, do governo federal brasileiro, responde parcialmente pelo aumento de seu emprego. A repercussão desse uso generalizado fragiliza sua operacionalidade teórica e promove sua banalização. O presente texto se propõe a discutir como o conceito foi apropriado e significado no mencionado programa governamental, problematizando as noções basilares de território rural e desenvolvimento territorial.
\end{abstract}

Palavras-chave | Brasil; desenvolvimento territorial; políticas governamentais; território; território rural.

Código JEL | O18; R11; R59.

THE POLICY OF RURAL TERRITORIAL DEVELOPMENT IN BRAZIL AND THE VULGARIZATION OF THE CONCEPT OF TERRITORY

\begin{abstract}
The term territory has been increasingly used in recent years. It has been used as explanatory category in order to understand the spatial dimension of society, as keyword for the formulation of public policies, and as motto for the strategies of social movements. Here we assumed the hypothesis that its capture by the Rural Territorial Development Policy, defined by the Ministry of Agrarian Development, of the Brazilian federal government, partly accounts for the increase of its use. The repercussion of this widespread use undermines its theoretical operability and promotes its vulgarization. In this article we intend to discuss how the concept of territory was appropriated and signified within the mentioned governmental program by questioning the basic notions of rural territory and territorial development.
\end{abstract}


Keywords | Brazil; government policies; rural territory; territorial development; territory.

JEL-Code | O18; R11; R59.

\section{LA POLÍTICA DE DESARROLLO TERRITORIAL RURAL EN BRASIL Y LA BANALIZACIÓN DEL CONCEPTO DE TERRITORIO}

\section{Resumen}

El término territorio nunca ha sido tan utilizado como en los últimos años, sea como categoría explicativa accionada para la comprensión de la dimensión espacial de la sociedad, sea como palabra-clave para la formulación de políticas públicas, o sea como lema para las estrategias de los movimientos sociales. Aquí se trabaja con la hipótesis de que su captura por la Política de Desarrollo Territorial Rural, del Ministerio de Desarrollo Agrario, del gobierno federal brasileño, responde en parte por el aumento de su empleo. Las repercusiones de este uso generalizado socava su funcionalidad teórica e promueve su banalización. Este trabajo se propone a discutir cómo el concepto fue apropiado y significado en el mencionado programa de gobierno, problematizando las nociones basilares de territorio rural e desarrollo territorial.

Palabras-clave | Brasil; desarrollo territorial; políticas de gobierno; territorio; territorio rural.

Código JEL | O18; R11; R59.

\section{Introdução}

Quem acompanhou a produção de conhecimento no campo das humanidades na primeira década do século XXI, certamente se assustará com a intensidade da presença do conceito de território, acionado como recurso explicativo para as mais variadas manifestações espaciais da sociedade. Essa constatação adquire maior expressividade se a observação se detiver no conhecimento geográfico produzido no Brasil. Trata-se mesmo de uma constatação comum, tamanha a evidência do fato, quando recorremos aos sumários de periódicos científicos e as listagens das teses e dissertações defendidas nos programas de pós-graduação em Geografia.

Todavia, o vocábulo se libertou das fronteiras acadêmicas e invadiu a esfera da ação governamental, tornando-se uma categoria chave para a formulação de políticas e programas de governo. Se nos detivermos ao Governo da Bahia, a constatação se torna intrigante, em decorrência da amplitude de sua aplicação, seja como divisão regional que sustenta o levantamento de informações das agências oficiais, seja por sua adoção na administração da ação governamental pelo interior do estado, conflitando com as tradicionais divisões regionais de planejamento e ação ${ }^{1}$.

\footnotetext{
${ }^{1}$ Refiro-me à tentativa de redefinir as áreas de atuação dos órgãos como DIREC (Diretoria Regional de Educação - Governo da Bahia), DIRES (Diretoria Regional de Saúde - Governo
} 
Não pode ser desprezada, também, a incidência da palavra nos discursos e nas estratégias dos mais distintos grupos e organizações sociais que compõem aquilo que contemporaneamente se entende, de modo vago e generalizado, como sociedade civil organizada. Os chamados coletivos sociais organizados que participam da atual política de desenvolvimento territorial do Governo Federal têm incorporado ao seu discurso cotidiano a palavra de modo impressionante (COELHO NETO, 2010, 2011), mesmo que seu significado seja ainda bastante obscuro e confuso. O conceito de território se tornou, também, um expediente cada vez mais recorrente e eficaz nas estratégias de luta e de reivindicação dos direitos das "comunidades tradicionais" e dos movimentos sociais (ALMEIDA, 2004), como, por exemplo, nos casos das populações quilombolas e indígenas.

Não estamos afirmando a inexistência do termo/conceito nos aludidos campos da sociedade antes da temporalidade mencionada, mas, sobretudo, destacamos que seu uso experimentou uma explosão na última década, caminhando rapidamente para um processo de banalização, que se caracteriza pelo uso trivial e pelo afrouxamento do sentido. $\mathrm{O}$ escrutínio dos modos de apropriação do vocábulo, recobrindo as mais distintas experiências nas quais vêm sendo utilizado, escapa aos propósitos e aos limites deste texto. Contudo, nos parece que, para o caso brasileiro, a instituição da Política de Desenvolvimento Territorial Rural pelo Governo do Partido dos Trabalhadores (PT), a partir de 2003, constitui um marco decisivo para o reforço e visibilidade do conceito de território, repercutindo em sua captura pelas diversas formas organizacionais que integram o amplo e crescente movimento de associacionismo, construído e intensificado no Brasil, nas últimas décadas.

Ressaltamos que na Política de Desenvolvimento Territorial Rural a categoria território é apropriada especialmente para fundamentar os conceitos de território rural e de desenvolvimento territorial, que são tratados com inconteste centralidade, conforme se pode constatar nos documentos oficiais que conferem sustentação à mencionada política ${ }^{2}$. Nesse sentido, salientamos que o presente texto dirige seu foco para o modo como a categoria território passou a integrar as mencionadas políticas territoriais, objetivado através dos dois conceitos acima aludidos, o que nos exigiu enfrentar a discussão dos conceitos de rural e de desenvolvimento.

Desse modo, estabelecemos a referida política territorial como recorte para as reflexões que desdobraremos neste texto. Antes, porém, esboçaremos em linhas

da Bahia), dentre outros, para atender as delimitações dos Territórios de identidade, contrastando com as antigas regionalizações desses órgãos.

${ }^{2}$ Refiro-me aos documentos analisados neste artigo e que se encontram listados nas referências bibliográficas ao final do texto: MDA (2005a, 2005b, 2005c). Uma breve visita aos títulos desses documentos permite-nos reforçar nossos argumentos. 
gerais seus pressupostos básicos e o contexto político-institucional de sua formulação e implantação, para, em seguida, nos debruçarmos sobre o conteúdo dos conceitos de território, território rural e desenvolvimento territorial, que tem alimentado discursos apaixonados na academia, na tecnoburocracia estatal e na sociedade civil organizada.

\section{A Política de Desenvolvimento Territorial Rural: contexto e pressupostos}

Nas últimas décadas do século XX, num cenário marcado pela redemocratização política e pela contestação da eficiência do Estado em gestar o território nacional, acentuado pela predominância do ideário neoliberal e pela ampliação da atuação dos movimentos da sociedade civil organizada, ocorreram fortes embates políticos e novas proposições sobre os modos de realização do planejamento e da gestão territorial.

As mudanças substanciais nos modos de concepção e operação das políticas governamentais decorrem dos esforços de organização da sociedade civil, da ação coletiva de uma gama diversificada de grupos, movimentos sociais, ONGs e inúmeras organizações que lutaram pela solução de graves problemas da sociedade brasileira (como as desigualdades socioeconômicas), pela cidadania, pela democracia, pelo respeito às diferenças culturais e pela autonomia política de diversos segmentos sociais (SCHERER-WARREN, 1999). Esses movimentos originaram-se na esteira da atuação sindical, dos partidos de esquerda e da vertente progressista da Igreja Católica (ALBUQUERQUE, 2004).

Esse cenário ganha novos contornos com o processo de redemocratização política e do amparo legal-institucional viabilizado pela Constituição de 1988. Verificam-se mudanças importantes nas últimas décadas: com o surgimento e proliferação de espaços públicos de discussão e decisão política, indicando o alargamento da atuação da sociedade civil organizada; com o aumento do número dos movimentos sociais e a densificação dos fenômenos de associativismo e cooperativismo; com a ampliação das redes sociais de solidariedades em escala regional, nacional e global entre movimentos sociais, organizações não governamentais e a população; e com a ampliação dos fóruns sociais de debate sobre relevantes questões públicas e o crescimento do processo de participação de diversos segmentos representativos da sociedade. Esses processos ajudaram a construir o envolvimento da sociedade civil, redefinindo as relações EstadoSociedade (NOGUEIRA, 2005).

Entretanto, Dagnino (2004) apresenta uma leitura crítica sobre esse contexto, identificando dois movimentos que operam dialeticamente, formando uma confluência perversa, unindo e opondo, de um lado, 
o projeto neoliberal que se instala em nossos países ao longo das últimas décadas e, de outro, um projeto democratizante, participativo, que emerge a partir das crises dos regimes autoritários e dos diferentes esforços nacionais de aprofundamento democrático (DAGNINO, 2004, p. 140).

Desde o estabelecimento da democracia formal, em 1985, e a aprovação da Constituição de 1988, foi sendo gestada gradativamente uma série de dispositivos legais para assegurar os princípios constitucionais, resultando na adoção de mecanismos de gestão, execução e controle social de políticas públicas, justificados em nome da democracia e assentados no discurso da participação social, do exercício da cidadania e do protagonismo da sociedade civil.

Um fato expressivo recente que repercutiu para o avanço desse processo foi a ascensão política do Partido dos Trabalhadores (PT), conquistando o mandato em várias prefeituras municipais no Brasil e, principalmente, a eleição de sua principal liderança para a Presidência da República em 2002. O PT foi gestado na esteira do movimento sindical, conseguindo disseminar suas bases nos movimentos sociais urbanos e rurais brasileiros. Em decorrência desta origem histórica ligada aos movimentos populares e das exigências morais que este vínculo exigia, assim como pelas possibilidades de ganho eleitoral, o discurso da participação social adquiriu maior ênfase, permitindo que os espaços de participação fossem incentivados/ativados, criando uma propensão ao associativismo ${ }^{3}$.

A ação política mais contundente e de maior visibilidade do Governo Lula (20032010), em termos de adoção discursiva dos princípios participativos, foi a elaboração da Política de Desenvolvimento Territorial Rural. Implantado em 2003, o Programa Nacional de Desenvolvimento Sustentável dos Territórios Rurais (PNDSTR) - como instrumento da referida política - gerido pelo Ministério de Desenvolvimento Agrário (MDA), pressupõe a construção de projeto político e de gestão, compartilhados pelos diversos agentes territoriais, sejam as instituições públicas, organizações não-governamentais, entidades de classe, associações, cooperativas, enfim, todo um conjunto de sujeitos que produzem, vivem e interagem no território.

O referido programa originou-se de uma linha de ação do Programa Nacional de Fortalecimento da Agricultura Familiar (PRONAF), que destinava recursos para a construção de obras e aquisição de serviços comunitários, durante o período 19972002. A proposta trabalhava com a ideia de promoção do desenvolvimento, valorizando a escala municipal, instrumentalizado por uma gestão estruturada em

\footnotetext{
${ }^{3}$ Há uma variada literatura acadêmica que analisa as experiências brasileiras de implantação de mecanismos de participação na gestão governamental, especialmente nas prefeituras do PT. Um livro que apresenta um amplo panorama é AVRITZER, L.; NAVARRO, Z. A inovação democrática no Brasil: o orçamento participativo. São Paulo: Cortez, 2003.
} 
Conselhos Municipais de Desenvolvimento Rural (CMDR). Com o governo petista, o programa ganha outra dimensão com a elaboração de um conjunto de diretrizes que passam a referenciar a política e a gestão territorial no Brasil, ampliando as fronteiras da pasta do MDA e da ação do governo central, tornandose fundamento para atuação governamental num plano mais geral, e incorporado na esfera de atuação de alguns estados federados, como é exemplar o caso da Bahia, cujo controle estatal encontra-se capturado pelo Partido dos Trabalhadores, em consonância com o Governo Federal.

A concepção de política e gestão territorial que fundamenta o PNDSTR encontrase centrada na construção de uma nova institucionalidade que recebe o nome de território, apoiando-se na ideia de promoção do desenvolvimento territorial, no estabelecimento do espaço rural como foco de atuação, e da gestão social como princípio que pretende garantir o envolvimento da sociedade civil no processo de construção política. Nesta perspectiva, suas diretrizes pressupõem: (i) criação de colegiados territoriais, compreendidos como espaços públicos ou arenas decisórias, que se configuram como uma nova governança territorial; (ii) criação de mecanismos de participação e construção do protagonismo da sociedade civil, para fortalecer os processos de descentralização política e estímulo à autogestão dos territórios; (iii) e a construção e fortalecimento de redes de articulação de atores, instituições e programas para condução do processo de gestão das políticas territoriais ${ }^{4}$.

A formação dos territórios na política do Governo Federal tem como base os municípios. Os limites do recorte territorial se definem a partir da adesão ou saída dos municípios, dos respectivos colegiados ou conselhos territoriais. Os critérios de demarcação têm se conduzido principalmente pelas relações políticas no interior do recorte espacial instituído como território e secundariamente pelo sentimento de pertencimento e identificação à mesma realidade regional. Atualmente, a Secretaria de Desenvolvimento Territorial (SDT), especialmente criada para coordenar a política territorial do MDA, identifica a existência de 160 territórios rurais (40\% na região Nordeste), abrangendo 4.297 municípios (24\% na região Nordeste), dados que demonstram a expressão, atualidade e relevância do fenômeno para a sociedade brasileira ${ }^{5}$.

A política de desenvolvimento territorial opera a partir de uma constelação de conceitos, dentre os quais elegemos alguns como objeto de nossa reflexão, pela posição de centralidade que ocupam na referida política, mas, também, pela aderência que encontraram nas comunidades territoriais. Território é o conceito

\footnotetext{
${ }^{4}$ Não é propósito deste trabalho avaliar a efetividade desses pressupostos. Estamos apenas informando sobre quais bases o discurso político do Governo, através de sua política de desenvolvimento territorial, se estrutura.

${ }^{5}$ Dados obtidos em 10 de agosto de 2008 no endereço eletrônico: http://www.mda.gov.br/sdt.
} 
matriz, no qual os demais se desdobram. O Território Rural é considerado como nova institucionalidade, constituindo-se na base operacional para realização da política, e o desenvolvimento territorial como objeto de desejo, como palavra mágica e como propósito perseguido pelos agentes públicos e privados. Isso nos leva a formular algumas interrogações que guiarão a reflexão do próximo item: Como o território é definido PNDSTR? O que se entende por "território rural"? Como ele é concebido enquanto conceito e se institucionaliza como fato? Qual é a compreensão de ruralidade que sustenta o PNDSTR? E o desenvolvimento territorial, o que há de novo em seu conteúdo que o difere das outras formas de adjetivação do desenvolvimento: local, regional, sustentável?

\section{Território e território rural: confusões e limitações}

O PNDSTR é um componente da política governamental, elaborado e executado no âmbito do MDA, que assume a ideia de desenvolvimento rural como um de seus propósitos. Partindo-se do pressuposto de que uma política elaborada por um ministério que tem o campo como espaço-referência de sua atuação e que adota a denominação de territórios rurais como parâmetro de delimitação do espaço de ação da política, é possível inferir que a noção de rural seja balizadora, exigindo uma clara explicitação da compreensão que se tem sobre o termo como representação do real, aliada a uma leitura atual da realidade rural brasileira.

A primeira constatação significativa nos documentos referenciais que orientam a política dos territórios rurais do Ministério do Desenvolvimento Agrário é a ausência de uma bibliografia minimamente satisfatória que possa oferecer elementos para compreensão do rural em sua complexidade, no sentido da construção de uma representação do rural que possa nortear a definição de políticas e ações. A maior parte dos documentos simplesmente não indica as referências, a não ser como notas de rodapé. Apenas dois autores, José Ely da Veiga e Ricardo Abramovay, são mencionados, ignorando-se um grande número de pesquisas e autores que vêm se debruçando sobre o tema, empreendendo um esforço de compreender a ruralidade na atualidade.

Essa constatação talvez ajude a explicar a ausência de uma definição de rural adotada pelo programa, o que não acontece com a definição do território, amplamente informada. Isso nos permite depreender que embora os territórios sejam adjetivados de rurais, a noção de rural não ocupou posição de importância na construção dos referenciais dessa política, permitindo-nos elaborar os seguintes questionamentos: Qual é a representação de rural e ruralidade adotada pelo PNDSTR? É possível definir uma política de desenvolvimento rural, anunciada como pretensão do programa, se não está explicitada ou devidamente clara a compreensão do que seja o rural? 
Nos documentos referenciais demonstra-se uma tímida intenção de definição dos "territórios rurais", conforme verificamos na transcrição:

São os territórios (...) onde os critérios multidimensionais que os caracterizam, bem como os elementos mais marcantes que facilitam a coesão social, cultural e territorial, apresentam, explícita ou implicitamente, a predominância de elementos rurais. Nestes territórios incluem-se os espaços urbanizados que compreendem pequenas e médias cidades, vilas e povoados (MDA, 2005a, p. 28, grifo nosso).

Inicialmente, é necessário informar que a transcrição acima equivale à totalidade do texto de um dos tópicos dos documentos, intitulado "Território Rural", e que pretensamente pretende defini-lo. O conteúdo apresentado não consegue dar conta do intento, pois não esclarece o que seriam os mencionados elementos rurais. Parece-nos que houve muito mais uma preocupação em informar que o urbano faz parte dos territórios rurais do que propriamente explicitar o que se entende por rural. Os elementos rurais são objeto apenas de uma nota de rodapé, reproduzida a seguir:

\footnotetext{
Ambiente natural pouco modificado e/ ou parcialmente convertido a atividades agrosilvo-pastoris; baixa densidade demográfica população pequena; base na economia primária e seus encadeamentos secundários e terciários; hábitos culturais e tradições típicas no universo rural (MDA, 2005a, p. 28, grifo nosso).
}

A nota de rodapé, apêndice da definição de territórios rurais, faz alusão a quatro elementos como expressão do rural. Primeiro, se remete ao rural romantizado, muito próximo da interpretação dicotômica, opondo rural-natural e urbanoartificial. Segundo, toma o rural como agrícola, ignorando as interpretações que destacam o grau de interação e interdependência e, poderíamos dizer, inseparabilidade entre os setores, dividindo-os de forma tradicional (primário, secundário e terciário). Terceiro, prioriza variáveis (densidade demográfica e tamanho da população) que, embora operacionais/funcionais, consideramos bastantes limitadoras para expressar a complexidade e a riqueza do rural. No quarto elemento mais uma vez prevalece a ausência de clareza, pois não está explicitado o que seriam "os hábitos culturais e tradições típicas do universo rural"'.

Um trecho de outro documento publicado pelo MDA reforça que a compreensão de rural na política territorial se assemelha com o que Goméz (2001) denominou de ruralidade tradicional, ou o que Marques (2002) chamou de perspectiva 
dicotômica", uma vez que considera o campo como "espaços consagrados à produção primária”.

[...] território envolve, portanto, não somente os espaços consagrados à produção primária - os campos - mas também pequenas cidades e aglomerados populacionais e os agentes que são característicos desses espaços (MDA, 2005c, p. 7-8, grifo nosso).

Mesmo quando esboça uma perspectiva de não restringir o rural ao agrícola, não assume a complexidade e imbricação do funcionamento da economia hoje, que não distingue de forma tão simples e fácil os setores de atividades e suas interrelações socioeconômicas e espaciais, não contemplando as discussões das "novas ruralidades" ${ }^{7}$, como a pluriatividade e multifuncionalidades amplamente difundidas nos estudos de Carneiro (1998), Moreira (2005) e as "urbanidades no rural"8 proposta por Rua (2005), dentre outros.

[...] o rural não se resume ao agrícola. Mais do que um setor econômico, o que define as áreas rurais enquanto tal são as suas características espaciais: menor grau de artificialização do ambiente quando comparado com as áreas urbanas, a menor densidade populacional, $\mathrm{o}$ maior peso dos fatores naturais (MDA, 2005b, p. 8, grifo nosso).

Novamente se reforçam os elementos que já foram comentados anteriormente. A ruralidade não se define a partir de suas especificidades, mas do que não é urbano. Numa perspectiva bastante funcional e dicotômica, comparam-se as variáveis escolhidas e separa-se o é que urbano do que é rural, como se essa distinção fosse tão evidente no domínio do empírico. Não se ignora que tais elementos possam

\footnotetext{
${ }^{6}$ A perspectiva dicotômica concebe o campo em oposição à cidade, enfatizando as diferenças que tornam esses espaços distintos entre si. Geralmente o rural é relacionado ao velho, ao tradicional, ao atrasado, ao passado, um espaço periférico onde se realizam atividades agrícolas; o urbano, por sua vez, é associado ao novo, ao moderno, ao adiantado, ao futuro, um espaço central onde se desenvolvem atividades industriais, de comércio e de serviços.

${ }^{7}$ As "novas ruralidades" consideram a existência de mudanças na realidade rural brasileira que se manifesta em dois fenômenos: na intensificação da pluriatividade que não permite mais definir o rural exclusivamente pela atividade agrícola em face do surgimento de outras atividades não-agrícolas, desenvolvidas ou não pela população do campo; e pela crescente busca de meios alternativos de vida no campo por pessoas oriundas da cidade, movimento tributário do pensamento ecológico e do questionamento da sociedade baseada na aceleração promovida pelo ritmo da industrialização.

8 “'As 'urbanidades no rural' seriam todas as manifestações do urbano em área rurais sem que se trate esses espaços como formalmente urbanos” (RUA, 2005, p. 57).
} 
ser considerados para participar do esforço de definição da ruralidade, mas julgamos insuficientes para uma aproximação com a realidade que se manifesta como rural hoje.

Os documentos institucionais informam superficialmente a metodologia operacional adotada para delimitar os "territórios rurais". O processo inicia com a caracterização das microrregiões geográficas do Instituto Brasileiro de Geografia e Estatística (IBGE), baseando-se, especificamente, nas variáveis de densidade demográfica e população média para identificar as microrregiões rurais. Estas, "indicam, preliminarmente, de quais regionais deverão se revelar os territórios rurais a serem trabalhados prioritariamente" (MDA, 2005a, p. 28-29). Assim, as microrregiões são as bases espaciais para delimitar os "territórios rurais" a partir da comparação das variáveis elegidas aprioristicamente. Nessa perspectiva, à primeira vista, os territórios rurais seriam divisões do espaço definidas a partir de critérios pré-estabelecidos, indicando muito mais uma regionalização do espaço para efetivação de uma política governamental. É como se as regiões, vistas enquanto classe de área ${ }^{9}$, produto de uma regionalização, se transformassem em territórios como num passe de mágica.

Caracterização geral dos territórios rurais existentes, através da base de informações secundárias, geopolíticas e demográficas do Instituto Brasileiro de Geografia e Estatística (IBGE), referente aos municípios e às microrregiões geográficas do Brasil (MDA, 2005b, p 16).

As microrregiões rurais são aquelas que apresentam densidade demográfica menor do que 80 habitantes por $\mathrm{km}^{2}$ e população média por município até 50.000 habitantes (MDA, 2005a, p. 28, grifo nosso).

Nessa caracterização são identificados três grupos de territórios: os 'urbanos', os 'intermediários' e os 'rurais'. Estes últimos foram definidos como sendo aqueles que se identifiquem dentre microrregiōes geográficas que apresentam densidade demográfica menor que 80 habitantes $/ \mathrm{km}^{2}$ e população média por municipio de até 50.000 babitantes (MDA, 2005b, p. 16, grifo nosso).

A revelação definitiva de cada território somente ocorrerá quando sua população, através dos atores sociais, reconheça os seus elementos caracterizadores da coesão social e territorial, durante, ou logo após, o processo de construção da identidade e proposição de sua visão do futuro (MDA, 2005a, p. 29, grifo nosso).

Contrapondo a vasta literatura disponível, que envidou esforços para discutir o território como conceito e apresentar leituras sobre as manifestações das territorialidades, o mecanismo de delimitação dos territórios rurais parece indicar

9 Discussão realizada por DUARTE, A. C. Regionalização: considerações metodológicas. Boletim de Geografia Teorética, 10 (20), 1980; e, CORRÊA, R. L. Região e organização espacial. São Paulo: Ática, 1986. 
que esses territórios (territórios de identidade, adotados no caso das políticas governamentais na Bahia) podem ser construídos por decreto, ou delimitados a partir de indicadores demográficos. Aqui parece ignorar o território como unidade empírica e a complexidade que condiciona seu processo de construção, como, por exemplo, a questão dos limites/fronteiras, por expressarem relações de poder e de identificação com o espaço. Apesar do anúncio de um segundo momento em que os agentes sociais deverão validar a demarcação dos territórios, não se pode negar a complexidade das questões políticas e econômicas que influenciam esse processo. A demarcação dos territórios assume os limites municipais como parâmetros, carregando junto os conflitos emancipatórios e o jogo de interesses políticos que aí se constituem. A construção da identidade como foi colocada parece um fenômeno temporal e espacialmente simples, que se concretiza no decorrer do processo da implantação dessa política.

A classificação dos territórios em urbanos, intermediários (o que seriam?) e rurais, embora indique uma predominância, parece carregar os perigos das classificações generalizadoras e fragmentadoras da realidade, pelo grau de dificuldade de separar realidades tão imbricadas espacialmente. Embora reconhecendo as necessidades pragmáticas da política e do planejamento governamental, esforços no sentido de re-significação dos mecanismos adotados devem ser tentados com maior originalidade e complexidade.

\section{A reinvenção do desenvolvimento: a noção de desenvolvimento territorial}

A discussão em torno da pol(iss)êmica noção de desenvolvimento, por si só, exigiria um esforço para além do escopo deste trabalho, embora já existam numerosos textos que se ocuparam deste propósito. Aqui nos compete, em conformidade com os objetivos propostos, apenas realizar uma reflexão acerca da ideia de desenvolvimento territorial.

A noção de desenvolvimento tem exercido enorme fascínio (e mesmo se tornado um fetiche) para os acadêmicos, políticos, técnicos do planejamento, empresários, movimentos sociais, coletivos sociais organizados, organizações intergovernamentais, sendo reproduzido também nas expectativas políticas dos cidadãos. Uma avaliação dos conteúdos dos documentos oficiais (leis, decretos, resoluções, planos de ações, publicações administrativas, dentre outros), dos programas e discursos dos partidos políticos ou dos protocolos internacionais assinados entre Estados nacionais testemunham o fato que estamos acusando. Em nosso campo de observação, isto é, nas políticas públicas, atualmente o termo tem presença assegurada e exigência obrigatória quando se trata de planejar a ação do Estado para intervenção na realidade social que compõe o território nacional. 
No entanto, nos parece que a dificuldade de objetivação desta noção nos inúmeros esforços empreendidos pelo Estado (e não se trata de uma constatação restrita à realidade brasileira) tem fomentado uma série de adjetivações para o termo desenvolvimento, que vai sendo reinventado como resposta ao acúmulo de insucessos das investidas em seu nome. Desenvolvimento econômico, desenvolvimento social, desenvolvimento cultural, desenvolvimento regional, desenvolvimento humano, desenvolvimento sustentável, desenvolvimento urbano, desenvolvimento rural, desenvolvimento local, desenvolvimento socioespacial e desenvolvimento territorial são apenas algumas das noções adjetivadas mais usuais que informam a dificuldade de definição do termo (desenvolvimento) em si e a necessidade de sua qualificação. Esse amplo repertório elencado afirma, por um lado, a renovada vitalidade da noção, todavia, por outro lado, informa a enorme obsessão que por ela tem acadêmicos, técnicos do planejamento e políticos em sua tarefa de dar respostas às problemáticas de pesquisa e conferir concretude aos projetos de intervenção social.

No atual momento de formulação de políticas públicas no Brasil, e mesmo nos estudos interpretativos da realidade, o desenvolvimento territorial assumiu uma posição privilegiada. No entanto, isso não significa que as outras noções foram olvidadas e retiradas de cena, mas continuam compondo o confuso repertório conceitual - especialmente no caso que queremos sublinhar - das concepções das políticas governamentais. Diante desta constatação é inevitável que algumas indagações se imponham como necessidade: afinal, o que há de novo em termos de conteúdo na adoção do termo desenvolvimento territorial? Ela encarna a pretensão de superar/substituir as demais noções existentes? O que se oferece como novidade que permite viabilizar essa superação?

Uma primeira constatação relevante recai sobre a geograficidade das qualificações do desenvolvimento. Como é possível depreender, a grande maioria das noções adjetivadas acima mencionadas faz referência a uma perspectiva espacial ou enfatiza a dimensão espacial da realidade, através dos termos urbano, rural, regional, local, socioespacial e territorial.

Cunha (2006) considera que a adoção da perspectiva espacial, mormente nos casos do desenvolvimento local, desenvolvimento sócio-espacial e desenvolvimento territorial equivale ao esforço de superar a setorialização presente nas tradicionais concepções historicistas e economicistas de desenvolvimento, buscando incorporar à análise a questão da

[...] simultaneidade, da diversidade, do caráter integrador e de síntese, da interação homem-natureza, da superação das distâncias, da territorialização e deslocalização das atividades econômicas, da dimensão territorial do desenvolvimento [...] (CUNHA, 2006, p. 274). 
Segundo Veiga (2002, p. 13), a noção de desenvolvimento territorial foi gestada no âmbito da Organização para a Cooperação e Desenvolvimento Econômico (OCDE) para contexto europeu, cuja adoção de uma perspectiva espacial de desenvolvimento teve como propósito "[...] aumentar a capacidade competitiva de territórios cuja integração no processo concorrencial é inadequada, e limitar os efeitos negativos de uma concorrência exacerbada".

Para o autor, o uso da noção desenvolvimento no contexto europeu teve como pretensão substituir as noções de planejamento e ordenamento, de caráter notadamente descendente, com orientação vertical. Já a noção adjetivada desenvolvimento territorial surge para substituir a tradicional expressão desenvolvimento regional, uma vez que "[...] permite uma referência simultânea ao desenvolvimento local, regional, nacional, e até continental (no caso da Europa)" (VEIGA, 2002, p. 17). Em relação ao desenvolvimento local, o desenvolvimento territorial implica pensar na interação das escalas espaciais e não apenas considerar uma escala de modo isolado (a local).

Em síntese, a noção de desenvolvimento territorial, defendido pelas políticas públicas em curso no Governo Federal, enfatiza a superação do viés setorial, pressupondo pensar o desenvolvimento para além dos setores primários, secundário ou terciário, permitindo também um tratamento integrado da dimensão espacial, urbana e rural, ou as diversas escalas espaciais. E, por outro lado, pressupõe a adoção de medidas de políticas mais democráticas e horizontais em oposição à extrema verticalidade e centralização que as caracterizou no passado recente. É o que fica explicitado na avaliação de Delgado et al. (2007, P. 29) sobre o Programa Nacional de Desenvolvimento Sustentável dos Territórios Rurais (PNDSTR):

De uma forma geral, o novo enfoque aponta para o rompimento com a visão centralizadora dos processos de elaboração das estratégias de desenvolvimento, como sendo fruto de uma lógica vertical e descendente. [...] pensar a própria territorialização das ações para o desenvolvimento, bem como novas iniciativas de operacionalização, numa perspectiva que aborda o local a partir de suas potencialidades endógenas em constante articulação e coordenação com os fluxos e as iniciativas exógenas, normalmente com relação aos núcleos urbanos e as escalas mais ampliadas. [...] o desenvolvimento territorial requer o planejamento e a coordenação das diferentes iniciativas públicas, sejam elas governamentais ou não, articulando-as de maneira a mantê-las coerentes com a estratégia de desenvolvimento negociada e conformada pelos diferentes atores sociais que fazem parte daquele mesmo território.

Para efeito de análise, reproduzimos alguns fragmentos dos documentos institucionais do Ministério do Desenvolvimento Agrário, especialmente aquele 
que apresenta as referências para uma estratégia de desenvolvimento rural sustentável no Brasil. Vejamos o que informa seu conteúdo:

Um dos pontos fundamentais desta proposta é apontar para uma nova maneira de conceber e de implementar políticas públicas que enfatizem o 'desenvolvimento rural sustentável (MDA, 2005a, p. 5, grifo nosso).

Mas o cardápio de mudanças é bastante amplo. Fundamentalmente esta proposta questiona a tradição de se implementarem planos de governos através de políticas e programas que elegem setores, ou segmentos da sociedade, como objetos permanentes de ação. [...] A sustentabilidade e a governabilidade somente atingirá niveis expressivos se os projetos compensatórios e assistenciais evoluirem para projetos de desenvolvimento regional (MDA, 2005a, p. 5, grifo nosso).

Para que esse processo aconteça em todo território nacional e para que ele se transforme em uma efetiva conquista democrática, será necessário promover o desenvolvimento rural a partir de uma perspectiva territorial. Nada mais inovador do que estimular o desenvolvimento endógeno [desenvolvimento local, portanto] dos territórios, partindo da ampliação da capacidade de mobilização, organização, diagnóstico, planejamento e autogestão das populações locais (MDA, 2005a, p. 11, grifo nosso).

Uma primeira constatação se refere à constelação de conceitos confusamente combinados com a qual opera a proposta da política pública (um cardápio amplo, como se admite no próprio texto da publicação governamental). $\mathrm{Na}$ mesma página, o documento consegue trabalhar e afirmar variadas noções adjetivadas de desenvolvimento: rural, rural sustentável, regional, endógeno (local), para tratar de sua noção fundadora, ou seja, o desenvolvimento territorial.

Não se pode ignorar que a noção de desenvolvimento territorial se origina no contexto europeu, portanto, trata-se de mais uma noção transplantada para a realidade brasileira e vendida como novidade, acusando nossas origens coloniais e atestando a mutilação de nossa criatividade e inventividade. No entanto, enquanto a proposição europeia anunciou a substituição das tradicionais noções de desenvolvimento regional e rural em decorrência dos resultados insatisfatórios das experiências por elas inspiradas (VEIGA, 2002), a política de desenvolvimento territorial brasileira mantém confusamente combinadas estas noções.

A permanência das noções de desenvolvimento regional, rural e local torna-se intrigante, afinal, uma das virtudes anunciadas para justificar a adoção de uma abordagem territorial foi justamente a superação da verticalização e centralização que caracterizaram as políticas de desenvolvimento regional, como também as possibilidades de tratamento integrado da dimensão espacial, não se restringindo ao rural ou ao local. 
O principal argumento para adoção da abordagem territorial - superação do viés setorial das políticas públicas - é outro aspecto contraditoriamente apresentado nos documentos referenciais, como se pode ler na transcrição abaixo:

O que aqui denominamos de 'ordenamento' tem o sentido geral do termo já utilizado nas Ciências Ambientais e na Geografia, mas com algumas diferenças fundamentais. Vai mais além da caracterização, localização ou destinação da ocupação espacial de um território. De fato, trata-se do ordenamento técnico, social, jurídico e político de que se revestem as políticas públicas, expressas nas mais diversas formas, geralmente estimulando on restringindo atividades, apoiando esse ou aquele setor on região (MDA, 2005a, p. 27, grifo nosso).

Primeiramente é preciso assinalar um equívoco de partida, ou seja, a simplificação sobre o entendimento do ordenamento na geografia, restrito no texto a localização e caracterização da ocupação espacial. A origem do uso da palavra desenvolvimento (indicando um movimento ascendente) para o contexto europeu encontrou motivação na substituição dos termos planejamento e ordenamento (de caráter descendente), embora no caso francês preferiu-se manter os termos adotando a noção de l'aménagement et le développement du territoire (VEIGA, 2002). O conteúdo do documento acaba traindo princípios fundadores da abordagem territorial - sua perspectiva não setorial e integradora das escalas espaciais concebendo atividades de estímulo a determinado setor ou região. Nota-se também, ao longo do documento, uma confusão (ou, no mínimo, uma indistinção) entre território e região, fato que pode ser reforçado pela forma como os territórios rurais são concebidos, originados das microrregiões geográficas do IBGE (como foi analisado na seção anterior).

\section{Considerações finais}

A adoção do qualificativo territorial à noção de desenvolvimento na política de desenvolvimento territorial do MDA está relacionada basicamente a três argumentos, conforme especificamos em outro texto (COELHO NETO; LIMA, 2011):

a) A renúncia à ação verticalizada do poder público, que passa a estimular a descentralização e participação social no processo de elaboração e gestão das políticas públicas;

b) A adoção de uma perspectiva híbrida e multidimensional do desenvolvimento, considerando as dimensões econômica, social, ambiental e político-institucional, 
em contraposição as abordagens setoriais que acabavam excluindo as parcelas historicamente negligenciadas na sociedade brasileira;

c) A valorização das raízes histórico-geográficas do território, das redes sociais e de solidariedade, enquanto processos endógenos de desenvolvimento.

A avaliação que realizamos nas seções anteriores demonstra que a proposta de desenvolvimento territorial do Ministério do Desenvolvimento Agrário apresenta graves problemas teórico-conceituais (confusão de conceitos) e também de ordem metodológica (na delimitação dos territórios rurais). O conteúdo dos documentos oficiais, contraditoriamente, afirma e nega os mesmos pressupostos em decorrência da apropriação confusa e acrítica de uma constelação de conceitos.

O apelo ao conceito de desenvolvimento territorial e, por conseguinte, de território, torna-se uma tônica predominante, que parece garantir a superação da concepção setorial e exógena de desenvolvimento e ao mesmo tempo abranger a complexa dinâmica social. Assim, incorre-se num sério risco de sobrevalorização do conceito e de

[...] transformá-lo num conceito que não só, epistemologicamente, tem a pretensão de dar conta de toda a complexidade do espaço geográfico [...] como também, num sentido normativo, acaba se tornando uma verdadeira panaceia em termos de políticas públicas (HAESBAERT, 2010, p. 156).

O desdobramento da adoção do conceito de território na política governamental tem produzido outros desdobramentos na realidade social: a apropriação do termo pelas organizações sociais que participam dos colegiados territoriais implantados pelo Ministério do Desenvolvimento Agrário para efetivação da política territorial, seja na denominação das entidades ou na elaboração de seu planejamento estratégico e de seus projetos e planos de ação, seja no discurso cotidiano de suas lideranças (COELHO NETO, 2010, 2011). Entretanto, esse fenômeno carece de uma análise mais específica que não cabe no escopo deste trabalho e que deixamos como provocação para o futuro.

\section{Referências}

ALBUQUERQUE, M. do C. Participação cidadã nas políticas públicas. In: Fundação Konrad Adenauer. Participação Cidadã: Novos conceitos e Metodologias. Fortaleza: Expressão Gráfica e Editora, 2004. 
ALMEIDA, A. W. B. de. Terras Tradicionalmente Ocupadas: Processos de Territorialização, Movimentos Sociais. Revista Brasileira de Estudos urbanos e Regionais, Rio de janeiro, v. 6, n. 1, mai., 2004.

CARNEIRO, M. J. Ruralidade: novas identidades em construção. Estudos, Sociedade e Agricultura, Rio de Janeiro, n. 11, p. 53-75, out., 1998.

COELHO NETO, A. S. Emergência e atuação das redes de coletivos sociais organizados no Território do Sisal. In: COELHO NETO, A. S.; SANTOS, E. M. C.; SILVA, O. A. (Orgs.). (Geo)grafias dos movimentos sociais. Feira de Santana: UEFS Editora, p. 305-368, 2010.

- Redes sociais e territorialidade no semi-árido brasileiro. Revista Geográfica de América Central, San José, v. 2, número especial EGAL, p. 1-18, II semestre de 2011.

COELHO NETO, A. S.; LIMA, J. S. Desenvolvimento Territorial e Economia Solidária: confluências e dissonâncias na política de desenvolvimento rural no Brasil. Revista Geográfica de América Central, San José, v. 2, número especial EGAL, p. 1-16, II semestre de 2011.

CUNHA, L. A. G. Do desenvolvimento setorial ao desenvolvimento territorial. Redes, Santa Cruz do Sul, v. 11, n. 2, p. 261-282, mai./ago., 2006.

DAGNINO, E. Construção democrática, neoliberalismo e participação: os dilemas da confluência perversa. Política \& Sociedade, Florianópolis, n. 5, p. 139-164, out., 2004.

DELGADO, N. G. et. al. Desenvolvimento territorial: articulação de políticas públicas e atores sociais. Relatório parcial. Rio de Janeiro: IICA/OPPA, 2007.

GOMÉZ, S. Nueva Ruralidad? Um aporte al debate. Estudos, Sociedade e Agricultura, Rio de Janeiro, n. 17, p. 5-32, out., 2001.

HAESBAERT, R. Território e região no desafio dos conceitos para uma política de ordenamento territorial. In: COELHO NETO. A. S.; SANTOS, E. M. C.; SILVA, O. A. (Orgs.). (Geo)grafias dos movimentos sociais. Feira de Santana: UEFS Editora, 2010.

MARQUES, M. I. M. O conceito de espaço rural em questão. Terra Livre, São Paulo, ano 18, n. 19, p. 95-112, jul./dez., 2002. 
MOREIRA, R. J. Identidades sociais em territórios rurais fluminenses. In: MOREIRA, R. J. (Org.). Identidades sociais: ruralidades no Brasil contemporâneo. Rio de Janeiro: DP\&A, 2005.

MDA. Referências para uma Estratégia de Desenvolvimento Rural Sustentável no Brasil. Documentos Institucionais, n. 1. Brasília: MDA/SDT, 2005a.

. Marco Referencial para Apoio ao Desenvolvimento de Territórios Rurais. Documentos Institucionais, n. 2. Brasília: MDA/SDT, 2005b.

. Referências para a Gestão Social de Territórios Rurais. Documentos Institucionais, n. 3. Brasília: MDA/SDT, 2005c.

NOGUEIRA, M. A. Um Estado para a sociedade civil: temas éticos e políticos da gestão democrática. 2. ed. São Paulo: Cortez, 2005.

RUA, J. A Resignificação do Rural e as Relações Cidade-Campo: uma contribuição geográfica. Revista da ANPEGE, Fortaleza, v. 2, n. 2, p. 45-66, 2005.

SCHERER-WARREN, I. Cidadania sem fronteiras: ações coletivas na era da globalização. São Paulo: Hucitec, 1999.

VEIGA, J. E. A face territorial do desenvolvimento. Interações - Revista Internacional de Desenvolvimento Local, Campo Grande, v. 3, n. 5, p. 5-19, Set., 2002.

Endereço para correspondência:

Agripino Souza Coelho Neto - ascneto@bol.com.br

Rua Silveira Martins, 2555, Cabula

41150-000 Salvador/BA, Brasil 